To be published in Area (accepted for publication $10^{\text {th }}$ November 2015)

\title{
Can people talk together about their practices? Focus groups, humour and the sensitive dynamics of cleanliness in everyday life
}

\author{
Alison L. Browne \\ Affiliation: Sustainable Consumption Institute and Geography, The University of Manchester \\ Address: Arthur Lewis Building (Geography Level 1), Oxford Road, The University of Manchester, \\ Manchester, United Kingdom, M139PL \\ Email: alison.browne@manchester.ac.uk
}

Acknowledgements: This research was funded by the ESRC/DEFRA/Scottish Government Sustainable Practices Research Group (SPRG) 'Patterns of Water' project (RES-597-25-003). I would like to thank the participants for generously giving up their time, stories and laughter in the focus groups. Big thanks to Will Medd, Beccy Whittle and Dave Horton who used their own time to co-facilitate the focus groups with me, and for approaching them with a serious lightness; the anonymous reviewers and Area editors for their helpful suggestions during review; and David Evans, Daniel Welch and Tullia Jack for their invaluable comments on an earlier draft. 


\section{Abstract}

The exploration of everyday social practices related to sustainability often touches on the most invisible parts of peoples' everyday lives. Given the multiple cultural forces that govern cleanliness and comfort, and the intimate spheres in which these practices are performed, practices associated with everyday water use (and associated energy consumption) bump up against 'the taboo'. While it has been resolved that 'people can talk about their practices' in interviews, a range of other methods - including CCTV, video and other data to survey and document practices in homes - are increasingly being used. As we delve theoretically closer to these public/private boundaries with new studies on social practices and sustainability, greater attention to the ethics of methods is needed. Different 'talk' based methodologies such as focus groups that could allow researchers to work more ethically with the strong moral sensitivities of certain domestic practices have not yet been considered. This article explores 6 focus groups on 'bodies, clothes, dirt, and cleanliness' which took place in Lancaster, UK. Reflecting on researcher positionality, and results of a survey of focus group participants following the focus groups, the paper concludes that focus groups, humour and laughter enable intimately political conversations about aspects of everyday practices that might be difficult to access or articulate through other research methods. The implications of using conversational humour and laughter as a purposeful tools for exploring particular aspects of everyday social practices is also explored. This article responds to recent calls for greater consideration of fieldwork and methodologies ethics related to gender and embodiment within human geography, and on the ethics and politics of everyday life research.

\section{Introduction}

The probing of everyday practices related to water and energy resource consumption pushes us ever closer to the intimate, and social, dynamics of the home (Kaufmann, 1998) including strong (gendered) moral sensitivities (Pink, 2004). This paper addresses the ethics and instrumentality of focus group methods in understanding dynamics related to cleanliness and hygiene of homes, clothes and bodies. It explores the role of humour and laughter - specifically in relation to focus groups - as a research strategy for awkward research encounters with everyday practice. This article is situated in a questioning of the methodological development of theories of social practice (e.g., Martens et al., 2014), debates which have become revitalised through the mainstreaming of different practice theoretical approaches to everyday life research and sustainable consumption. It also contributes to debates about the limits, benefits and moralities of talk based methodologies as they relate to everyday life, domestic practices and consumption more broadly conceptualised (e.g., Muir and Mason, 2012), and geographical literatures on focus groups (Holbrook and Jackson, 1996, Hopkins, 2007, Koch, 2013, McGregor, 2004). The arguments presented also connect with the call for greater consideration of fieldwork and methodologies related to bodies, gender and embodiment in human 
geography (Longhurst and Johnston, 2014). This paper emphasises that ethical and moral sensitivities regarding domestic practices should be central to the construction and implementation of methodology within everyday geographies. It is argued that focus groups and a connection with humour enables the collection of data about performativity as linked to social conventions beyond that possible with interviews, observational methods and ethnomethodology.

Waves of criticism and defence of talk based methodologies have a strong lineage; embedded in critiques of representational ontologies and an increased engagement with the material, the corporeal, and the performative (e.g., Harrison, 2007). Critiques of talk tend to centre on what it doesn't capture (Martens, 2012b). Sensory, visual, observational, and (new forms of) quantitative and experimental methodologies (e.g., Browne et al., 2014, Davies and Doyle, 2015, Latham, 2003) are increasingly promoted as ways to overcome the limitations of talk based ethnographic work in the home (Martens, 2012b). However, Hitchings (2012) defends the humble interview - and talk more generally - as a useful method to capture practice, although he cautiously reflects not all people can talk freely and that some practices might be more difficult to access in one-to-one 'talk' based methods (see also Mason and Davies, 2009).

The creative use of methods has proven essential to the theoretical development of social practice theories and their application in sustainable consumption research (eg., Browne et al., 2015, Martens et al., 2014). Many researchers are now exploring new ways to capture performance of practices and their material, performative, and conventional entanglements. Amongst this proliferation of research techniques to understand everyday life, the consideration of the ethics and politics of method is crucial (Halkier, 2011, Halkier et al., 2011, Martens, 2012a) as they bring the researcher closer to the intimate dynamics of participants' everyday lives, their bodies and related cultural and infrastructural intersections (Royston, 2014, Wallenborn, 2013).

The mundane, potentially awkward nature of everyday social practices related to resource consumption in the home means that questions about the impacts and implications of methodological choices for social practices research becomes incredibly important. It is worth considering the different kinds of awkwardness that may emerge in talk about everyday practices, and the methodological strategies that might overcome them. There may be different ways of working with potential awkwardness in talking about lay normativity in regards to sustainable consumption (Barnett et al., 2011) compared to potentially shameful feelings around 'dirty topics' (Longhurst, 2001) such as stains in your laundry (Jack, 2013) or bodies that sweat (Waitt, 2014, Waitt and Stanes, 2015). For example, gossiping about others in interviews (distinguishable to with others 
during group research) can overcome awkwardness and enables access to cultural norms underpinning thermal comfort (Hitchings and Day, 2011).

Different methodologies are required to get at the rhythms, routines and dynamics underpinning different types of practices. Methodologies that are appropriate for studying 'public' practices like sport (e.g., Blue, 2013) and mobilities (e.g., Spinney, 2009) may not be appropriate for capturing the dynamics of cleanliness practices that - in the Global North at least, but increasingly in the Global South - largely take place in the privacy of peoples' homes and bathroom spaces (Elias, 2000, Srinivas, 2002). While CCTV, video and sensory ethnographies more generally, can be useful for exploring performances of household practices such as dishwashing (Martens, 2012b), they are potentially inappropriate for capturing the meanings (social conventions) related to other forms of cleanliness, or capturing the actual performances of personal washing and bathing. How methods relate to specific (theoretically driven) research questions is also important, for example, whether the research is trying to capture consumption as it relates to: performances and entities at a population level (Browne et al., 2015); materiality (Evans, 2014); know-how and skills (Royston, 2014); the social organisation of practices (Shove et al., 2014); or bundles of practices (Gram-Hanssen, 2011).

Notably absent from this increasing list of methods to explore everyday practices is focus groups. The human geography literatures on focus groups show how a methodological tool used extensively within market research and consumer sciences (Grandclément and Gaglio, 2011, Holbrook and Jackson, 1996) has been adapted to address the core interests of human geography, including issues of power and performativity embedded in research processes (e.g., Koch, 2013). Within human geography, focus groups are espoused as offering opportunities for the research process to spark political action and as a way to explore with participants difficult-to-access experiential knowledges, opinions and meanings (Hopkins, 2007), identities (Holbrook and Jackson, 1996), environmental discourses and social knowledges (McGregor, 2005), and "everyday engagements with ... social and spatial worlds" (Hopkins, 2007, p. 529). They are perhaps particularly useful when other qualitative research methods are found to 'close' off awkward and politicised experiences and encounters (Hopkins, 2007, Koch, 2013). However, there has been little discussion about their suitability as potential method to enable intimately political conversations about aspects of everyday practice that might be difficult to access or articulate.

The ability to create a space within focus groups for shared stories, laughter and gossip is also relevant here (McGregor, 2004). Although the role of humour and laughter is increasingly explored as a tool for research within geography (Delph-Janiurek, 2001, Ridanpää, 2014), it has not yet developed 
in geographical literatures on focus group methodology. Within other social sciences (health, education, psychology) laughter and humour is emphasized within focus group methods as a way of overcoming social awkwardness around taboo and shameful topics, particularly with marginalised groups (Robinson, 2009). Within these literatures, the focus group is thought to create an important social space to enable generation of data that would otherwise be inaccessible through one-to-one methodologies (Wilkinson et al., 2007). We toyed with the idea that conversational humour as a research tool within focus group methodology might be a useful way of creating a safe social space to talk about sensitive and intimate practices related to resource use in the home.

\section{Reflections on the Use of Focus Groups and Humour to Capture Dynamics of Everyday Practices}

The focus group research detailed below was embedded in a wider set of research activities that attempted to understand the diversity and patterns of water use associated with laundry, personal care (washing, bathing, showering), gardening and kitchen water use across a population of South East England (Pullinger et al., 2013). Our mixed methods strategy drew upon an 1800 person quantitative survey and 22 qualitative interviews with survey participants. The data enabled us to capture a snapshot of how cleanliness practices have changed over time in the UK, and reflect on their potential future trajectories (Browne et al., 2015). However, it was difficult to reflect deeply in the quantitative and qualitative interview data on the way that (shared) cultural conventions shape diversities and patterns of cleanliness practices related to self/personal care and care of others (Shove, 2003).

It was also recognised early on in the quantitative and qualitative aspects of this mixed methods strategy, that detailed questions about practices underpinning water consumption - particularly those related to clothes, bodies, and general cleanliness - could be quite awkward. For example, despite significant consideration and investments in research techniques (e.g., piloting surveys, computer assisted program interviewing) by the research team and the commissioned market research company to overcome the sensitive nature of the survey, our survey had some of the highest refusal rates and follow up complaints the market research company had experienced. The qualitative interviews also revealed how talk of showers and laundry can often slip into the intimate, which the framing of an interview on water use did not prepare the participants for. Such lines of inquiry were often quickly shut down or made light of by the participant once they recognised the conversation may be 'inappropriate' and 'uncomfortable'. 
Our research methodologies were increasingly pushing up against the intimacies of personal lives, the material realities (and taboos) of lived sexual/gendered (and in some conversations aging or differently-abled) bodies, and the vital materiality of symbolic dirt (Bennett, 2010, Campkin and Cox, 2007, Waitt, 2014). Although underpinned by similar concepts of dirt and cleanliness, we reflected upon the difficulties of getting at the (intimate) dynamics of 'private' practices like bathing and washing (of self, others, and clothes) compared to other cleaning practices such as dishwashing (Martens, 2007) during interviews. There was also a question as to whether these potentially awkward practices (and the complex social and cultural dynamics of cleanliness underpinning them) were more or less amenable to verbal articulation between people in the setting of a focus group framed through conversation and humour.

\section{Setting up the focus groups}

We experimented with different group structures which has previously been reported to influence group dynamics, for example, whether a group is made up of friends or social acquaintances (Coates, 1996, Hay, 2000, Holbrook and Jackson, 1996), or complete strangers (Wilkinson et al., 2007). For the first two focus groups we recruited participants from two (gender separated) community groups in Lancashire, UK. One group was a male sporting group and the second a female music group. The second strategy was to recruit through snowball sampling (flyers handed out at the university square at lunchtime, emails, Facebook invitations snowballed throughout university and personal/professional networks). For this second strategy there were four gender separated groups: a male and female under 24 years old focus group (undergraduate and early postgraduate students, as well as young professionals), and an over 24 year old focus group (postgraduates, professionals). Due to the snowballing strategy used and the small size of Lancaster University and Lancaster town there was a mix of strangers and acquaintances in these four focus groups. Groups were split by gender due to the different functions of humour, funny stories, jokes and teasing in male and female conversations and the anticipated sensitive nature of the conversation (Bing, 2007, Gouin, 2004, Hay, 2000). For both structures of the focus group the recruitment flyer specifically highlighted that the sessions were about bodies, clothes and cleanliness (rather than water or energy use), and would be fun and interactive.

Location, places and times of day of focus groups matter (Hopkins, 2007) and as conversational informality was desired the events were held in rooms at a local community centre and pub, in the evening with food and drinks for the participants, and took two hours. Each focus group had only 7-9 participants (Barbour, 2008), and two facilitators who were the same gender as the participants. 
Participants were given a $£ 20$ supermarket voucher for participating ${ }^{1}$ (see Grady, 2001, Head, 2009). The session was structured to be casual, fun and interactive but without expectation (of ourselves or the participants) of how or why they would be funny. The positionality of research/ers was made explicit and discussed within preparatory sessions with facilitators (England, 1994, Rose, 1997). This flowed into the style of facilitation to 'be curious with participants' about the topics under discussion and encouraging participants to question and have conversations around each other's practices and habits rather than just rely on facilitators' questions. Participants were also given the opportunity to feedback on their experience in the focus group through an online evaluative survey.

\section{Evaluating focus groups: Sharing stories, humour and incongruity}

As the quote below describes, there can be strong sexual humour within all female groups (Bing, 2007), with sharing funny personal stories a route to female group solidarity (Hay, 2000). 'Conversational humour' is also said to become characterised in group settings by "overlapping speech, the co-construction of utterances, repetition, and a heightened use of metaphorical language" (Coates, 2007, p. 1). This interview transcript was from the over 24s female focus group about bed sheets (italics were added during transcription):

FACILITATOR $1 \quad$ So how often do people wash sheets and stuff?

They start talking over each other.

MARCIA I think it's the threshold thing [echoing an earlier discussion of acceptability of dirt] again isn't it! It's like you look at your sheets and you're like 'Oh Ewwwww'! [Eww used as disgust]

JULIA I wash them a lot because I drool a lot. Big time!

[laughter]

FACILITATOR 1 So you change them what, how often?

JULIA I'd say each other week and at home [South American country] every week just because it's hotter so I wake up in sweat even in the winter. After sex as well. [laughter]

FACILITATOR $1 \quad$ So do people change them after sex as well?

PENNY Sex yes, the more sex the more you have to change your bedding.

\footnotetext{
${ }^{1}$ Research participants were paid in order to respect the time given to volunteer for the research, in particular in consideration of people with limited incomes (students, unemployed, and part time workers), and to allow people with family responsibilities to participate (the focus groups took place in the evening and the $£ 20$ was considered to offset costs of babysitter).
} 
MARCIA So, every time you have sex you change your sheets?

PENNY No. No.

JULIA After the guy leaves?

PENNY If it's different guys it's just etiquette!

Cackles of Laughter

[someone interjects: it's just manners!]

VANESSA We usually change ours weekly but they are white so it's very quickly obvious if they're grubby or whatever.

FACILITATOR 1 And you do that like every ....?

VANESSA It's usually a Friday or Saturday so the weekend it's like nice. [FACILITATOR 1 interrupts: ah right clean sheets for the weekend? A few people agree with a few 'yeah yeahs'].

PENNY Yes clean sheets, it's nice to get into a bed as well with clean sheets.

MARCIA Clean sheets and shaved legs!

FACILITATOR 1 So they tend to go together? Do you change pyjamas when you put new sheets on?

MARCIA and a few others (indistinguishable who): Yes yes!

JULIA I I don't, I don't drool on the pyjamas. [laughter]

SUZI I'd definitely go three or four weeks before I change my sheets!

CAROLE You know I've been sitting here for a long time trying to remember when I changed my sheets last and I can't!!

Laughter

BELLE There was something on the news recently about changing your sheets and then that just made me cringe because I was like oh my god I need to change my sheets right now! It was talking about how long you leave them on for and what was the norm and then it was....

MARCIA Really and what is the norm?

JO I think it was supposed to be every two weeks but then most people they asked on the street was sort of like "oh yeaaaaah I do it every week" [using a very sarcastic voice indicating they wait much longer].

Cackles of Laughter

The emergence of humour amongst focus group participants, particularly sexual joke making, was more pronounced across the female focus groups as has been observed as a dynamic in other 
literatures (Bing, 2007, Hay, 2000). However, humour also worked as a facilitative tool across all of the focus groups regardless of gender. More generally, the focus group was a safe space in which to share stories - about themselves, their friends and families - in relation to something intimately familiar but rarely verbally shared. As desired, some parts of the focus groups became organic conversations and a form of gossip with other participants, rather than conversation just structured by the facilitators. Each of the focus groups were different in what - and how the - humorous stories were told, or shared. This was influenced by gender, and the structure of the focus group, that is, whether the group were mostly all strangers or members of a community of interest (discussed below). The role of the facilitator is also significant here, for example, in the male focus groups the facilitators reflected they had to work (differently across the groups) to find and then use a mode of humour that resonated with and worked for that group.

Through the telling of humorous stories, incongruences between participants about the nature of 'normal' bodies and routines were myth busted. It became obvious through the sharing of stories, humour, and the incongruences perceived that there was no 'normal'. Through humour these participants were discovering in real time new dimensions of the incongruity of their perceptions of what ought to be done (Roberts, 1988), and a sense of the presumed shared meanings associated with societal ideas about cleanliness and freshness, versus the diversity of what people actually do in their everyday lives. Intersecting these discussions was an idea of genuine surprise, and humour, at what inspired a change of bedding; understandings and thresholds of dirt; commentary on sexualities, beauty routines and feelings of freshness; and the societal norms of washing bodies, clothes and bedding reflected in the media.

\section{Participant reflections on the focus groups}

Participants were given the opportunity to take part in an online evaluative survey in the week following the focus group (using Survey Monkey). This survey asked detailed questions about their participation in the focus group and their views of the research process. There was a high response rate of $71.74 \%$ ( 33 people out of 46 who participated). Half of the participants were surprised at the topics of conversation ( $50 \%$ - with $37.5 \%$ agreed; $12.5 \%$ strongly agreed), but the overwhelming majority enjoyed discussing these topics (93.8\% - with $65.8 \%$ agree; $28 \%$ strongly agreed), and found the topics discussed interesting (96.9\% - with $56.3 \%$ agree; $40.6 \%$ strongly agree). In terms of the use of focus groups as a way to overcome a sense of discomfort in talking about the intimate aspects of practice, when asked if the topic of conversation made them feel uncomfortable the overwhelming majority disagreed (87.6\% - with $56.3 \%$ disagree; $31.3 \%$ strongly disagree). This supports previous 
research that has shown that focus groups are a successful way of discussing sensitive topics (Robinson, 2009, Wilkinson et al., 2007).

In terms of a sense of embarrassment $84.4 \%$ disagreed (50\% disagreed and $34.4 \%$ strongly disagreed) with the statement that they felt embarrassed by some of the topics of conversation. The evaluative survey shows the majority of participants did not feel embarrassed or uncomfortable about the topics of discussion but rather found it enjoyable and interesting. When probed further in open ended questions there were a wide range of answers. For the 32 participants who responded to open code questions their responses centred on themes of humour, a sense of sharing, a sense of liberation at the discussion, the role of facilitation and the setting, and peripheral anxieties.

For some the sharing of embarrassing or memorable stories across the group (an intentional strategy - we got each person to share a memory of being dirty as an icebreaker) was a leveller that made people feel comfortable. In the female community group being amongst a group with whom they shared common bonds and friendship helped (Kitzinger, 1994). However, for some participants in the community-of-interest groups, this sense of friendship and bonds created some level of anxiety about the level of sharing. Although participants were sharing stories about common experiences in everyday lives (Holbrook and Jackson, 1996), some were concerned about revealing too much about oneself, or intimate stories about a partner known to the rest of the group. Across all of the six focus groups, however, the sharing of the diversity of others practices, and the extreme ranges of habits and routines expressed made people feel more comfortable to share their own stories. Others reflected that they found the discussion "liberating", "frank and open" and that it was "good to talk about things that are just necessities of life!"

One of our hypotheses was that an informal focus group which used humour and laughter could be used as a way to get people to discuss fairly intimate aspects of everyday practice. A number reflected that the focus group was fun, interesting, humorous, amusing, and that there was a sense of surprise at the stories that emerged from the discussion. One participant reflected (the question did not prompt about the use of humour): "Short answer is humour. It was a comfortable group...I didn't think topics crossed awkward boundaries, for me at least". When asked if they felt uncomfortable or embarrassed by the topics of conversation the overwhelming majority (31 respondents) said 'no'. However for the two participants that did find these topics embarrassing it was about when the discussion turned to sex. 
Facilitation was a significant theme. The participants reflected that this was a safe, relaxed space where people were listened to and people could expect and offer honesty. Another reflection on facilitation was that it was good to split the focus groups according to gender, and that the recruitment strategy set clear expectations about the potential topics of discussion. Framing the conversations around bodies, clothes and cleanliness rather than water use was a significant issue - a number of people said how they had felt prepared to discuss intimate topics coming into the focus group, and there was not a sense of 'shock' about the content of the focus groups when sensitive topics were raised.

\section{Conclusions}

Despite critique, talk based methods remain one of the most widely used empirical tools to gain understandings of everyday life, consumption, and more recently sustainability (Barnett et al., 2011, Hitchings, 2012). Conversational focus group methods are rarely used within this literature but as this paper explores they can facilitate a different type of talk around social practices and everyday life. The excerpt about laundering bed sheets shows that in these focus group settings encouraging curiosity about others, openness and humour enabled the participants to explore what they found interesting or incongruent about each other's practices, and challenge held social norms and meanings. Focus groups or similar informal multi-person conversations in which humour and laughter feature enacts a new type of data (Robinson, 2009). The focus group is therefore a currently underused but potentially fruitful method to research mundane everyday practices as it allows new data to emerge particularly about social meanings and conventions, the social organisation of everyday practices, and connections across bundles of practices.

Another purpose of the article was to evaluate the success of focus groups in overcoming the awkwardness of individual talk based methods regarding everyday practice, and the range of ethical issues regarding methodologies of practice discussed in the introduction. This was evaluated through the follow up questionnaire - to judge the 'ethics' of focus group methods through the participants' own perspectives. The findings from the evaluative survey - and stated with confidence because of the high response rate - reflect that focus groups conversations around intimate dynamics of practice do not provoke feelings of awkwardness, embarrassment or discomfort. Conversely, most participants found the conversations interesting and enjoyable even when it bumped up against intimate and social dynamics in the home. How the focus groups were set up was important: groups were single gendered; participants had anticipated the topics of conversation; and a space was held open for 
lightness, laughter, and humour which were described by participants as important in invigorating conversations around awkward topics.

This article asserts that focus groups - particularly when they invoke humour and laughter - are a useful research strategy when exploring awkward, and socially taboo, research encounters around everyday practice and sustainable consumption. Like all 'talk based' research methods focus groups clearly have their limitations such as the focus group itself being a type of performance (Grandclément and Gaglio, 2011). However, they also have their strengths in that the focus group 'performance' also creates new types of data. For example, conversational incongruence revealed different aspects of (shared) social conventions and meaning making about practices, and the diverse material and social influences to everyday practice (infrastructures, technologies, dirt, others and own bodies).

In summary, by enabling people to talk together about their everyday practices focus groups can: enhance understandings of the diversity and dynamics of everyday practices; reveal particular ideas of shared routines and cultural conventions; challenge these social norms through the highlighting of incongruences between participants; highlight the connections between performativity, materiality and cultural conventions; and enable reflections on the negotiation of the dynamics and routines related to practices that underpin household water and energy sustainability. Understanding these dynamics will become even more significant as practices of cleanliness and other household practices evolve to become even more resource intensive (Browne et al., 2015), and increasing interest is given in research and policy about how to influence trajectories of sustainable consumption (Davies and Doyle, 2015, Evans et al., 2012). Importantly it has been highlighted that research on sustainability and everyday life needs to more critically attend to the personal, gendered, embodied, often intimate nature of practices under study; and that deeper reflection is needed on the ethics of research methods as social practice theories become mainstreamed in everyday life and sustainable consumption research. 
References

Barbour, R. 2008. Doing focus groups, London, Sage.

Barnett, C., Cloke, P., Clarke, N. \& Malpass, A. 2011. Globalizing responsibility: The political rationalities of ethical consumption, London, Wiley-Blackwell.

Bennett, J. 2010. Vibrant matter: A political ecology of things, US, Duke University Press.

Bing, J. 2007. Liberated jokes: Sexual humor in all-female groups. Humor, 20, 337-366.

Blue, S. 2013. Ongoing change in the rhythms of mixed martial arts practice. The International Journal of Sport and Society, 3, 161-170.

Browne, A. L., Medd, W., Anderson, B. \& Pullinger, M. 2015. Methodologies as intervention: Intervening in practice through quantitative and mixed methodologies In: STRENGERS, Y. \& MALLER, C. (eds.) Social practices, interventions and sustainability: Beyond behaviour change. UK: Routledge.

Browne, A. L., Pullinger, M., Medd, W. \& Anderson, B. 2014. Patterns of practice: A reflection on the development of quantitative/mixed methodologies capturing everyday life related to water consumption in the UK. International Journal of Social Research Methodology, 17, 27-43.

Campkin, B. \& Cox, R. 2007. Introduction: Materialities and metaphors of dirt and cleanliness. In: CAMPKIN, B. \& COX, R. (eds.) Dirt: New geographies of cleanliness and contamination. London: I.B. Tauris.

Coates, J. 1996. Women talk: Conversation between women friends, Oxford, Blackwell.

Coates, J. 2007. Talk in a play frame: More on laughter and intimacy. Journal of Pragmatics, 39, $29-49$.

Davies, A. R. \& Doyle, R. 2015. Transforming Household Consumption: From Backcasting to HomeLabs Experiments. The Annals of the Association of American Geographers, 105, 424-436.

Delph-Janiurek, T. 2001. (Un)consensual conversations: betweenness, 'material access', laughter and reflexivity in research. AREA, 33, 414-421.

Elias, N. 2000. The civilising process: Sociogenetic and psychogenetic investigations, Oxford, UK, Blackwell Publishing.

England, K. V. L. 1994. Getting personal: Reflexivity, positionality, and feminist research. The Professional Geographer, 46, 80-89.

Evans, D. 2014. Food waste: Home consumption, material culture and everyday life, London, Bloomsbury.

Evans, D., Southerton, D. \& Mcmeekin, A. 2012. Sustainable consumption, behaviour change policies and theories of practice. . COLLeGIUM: Studies across disciplines in the Humanities and Social Sciences, 12, 113-129.

Gouin, R. R. 2004. What's so funny? : Humor in women's accounts of their involvement in social action. Qualitative Research, 4, 25-44.

Grady, C. 2001. Money for Research Participation: Does It Jeopardize Informed Consent? The American Journal of Bioethics, 1, 40-44.

Gram-Hanssen, K. 2011. Understanding change and continuity in residential energy consumption. Journal of Consumer Culture, 11, 61-78.

Grandclément, C. \& Gaglio, G. 2011. Convoking the consumer in person: The focus group effect. In: ZWICK, D. \& CAYLA, J. (eds.) Inside marketing: Practices, ideologies, devices. Oxford: Oxford University Press.

Halkier, B. 2011. Methdological practicalities in analytical generalization. Qualitative Inquiry, 17, 787797.

Halkier, B., Katz-Gerro, T. \& Martens, L. 2011. Applying practice theory to the study of consumption: Theoretical and methodological considerations. Journal of Consumer Culture, 11, 3-13.

Harrison, P. 2007. "How shall I say it ... ?" Relating the nonrelational. Environment and Planning A, 39, 590-608.

Hay, J. 2000. Functions of humor in the conversations of men and women. Journal of Pragmatics, 32, 709-742. 
Head, E. 2009. The ethics and implications of paying participants in qualitative research. International Journal of Social Research Methodology, 12, 335-344.

Hitchings, R. 2012. People can talk about their practices. Area, 44, 61-67.

Hitchings, R. \& Day, R. 2011. How older people relate to the private winter warmth practices of their peers and why we should be interested. . Environment and Planning A, 43, 2457-2467.

Holbrook, B. \& Jackson, P. 1996. Shopping around: Focus Group Research in North London. Area, 28, 136-142.

Hopkins, P. E. 2007. Thinking critically and creatively about focus groups. Area, 39, 528-535.

Jack, T. 2013. Nobody was dirty: Intervening in inconspicuous consumption of laundry routines. Journal of Consumer Culture, 13, 406-421.

Kaufmann, J.-C. 1998. Dirty linen: Couples and their laundry, London, UK, Middlesex University Press.

Kitzinger, J. 1994. The methodology of focus groups: the importance of interaction between research participants. Sociology of Health and IIIness, 16, 103-26.

Koch, N. 2013. Technologising the opinion: focus groups, performance and free speech. Area, 45, 411418.

Latham, A. 2003. Research, performance, and doing human geography: some reflections on the diaryphotograph, diary-interview method. Environment and Planning A, 35, 1993-2017.

Longhurst, R. 2001. Bodies: Exploring fluid boundaries. , London, Routledge.

Longhurst, R. \& Johnston, L. 2014. Bodies, gender, place and culture: 21 years on. Gender, Place \& Culture: A journal of feminist geography, 21, 267-278.

Martens, L. 2007. The visible and the invisible: (De)regulation of contemporary cleanling practices. In: CAMPKIN, B. \& COX, R. (eds.) Dirt: New geographies of cleanliness and contamination. London: I.B. Tauris.

Martens, L. 2012a. The politics and practices of looking: CCTV and domestic kitchen practices. In: PINK, S. (ed.) Advances in Visual Methodology London: SAGE.

Martens, L. D. 2012b. Practice 'in talk' and talk 'as practice': Dishwashing and the reach of language. Sociological Research Online, 17.

Martens, L. D., Halkier, B. \& Pink, S. 2014. Introduction to Researching Habits: Advances in linguistic and embodied research practice. International Journal of Social Research Methodology, 17, 19.

Mason, J. \& Davies, K. 2009. Coming to our senses? A critical approach to sensory methodology. Qualitative Research, 9, 587-603.

Mcgregor, A. 2004. Doing groups: Situating knowledge and creating stories. Australian Geographer, $35,141-149$.

Mcgregor, A. 2005. Negotiating nature: exploring discourse through small group research. Area, 37, 423-432.

Muir, S. \& Mason, J. 2012. Capturing Christmas: The sensory potential of data from participant produced video. Sociological Research Online, 17, 5.

Pink, S. 2004. Home truths: Gender, domestic objects and everyday life, Oxford, Berg.

Pullinger, M., Browne, A. L., Medd, W. \& Anderson, B. 2013. Patterns of practice: Laundry, bathroom and gardening practices of households in England influencing water consumption and demand management [Final Report]. Lancaster, UK: Lancaster Environment Centre, Lancaster University.

Ridanpää, J. 2014. Geographical studies of humor. Geography Compass, 8, 7010-709.

Roberts, R. C. 1988. Humor and the virtues. Inquiry: An interdisciplinary Journal of Philosophy, 331, 127-149.

Robinson, J. C. 2009. Laughter and forgetting: Using focus groups to discuss smoking and motherhood in low-income areas in the UK. Journal of Qualitative Studies in Education, 22, 263-278.

Rose, G. 1997. Situating knowledges: positionality, reflexivities and other tactics. Progress in Human Geography, 21, 305-320.

Royston, S. 2014. Dragon-breath and snow-melt: Know-how, experience and heat flows in the home. Energy Research and Social Science, 2, 148-158.

Shove, E. 2003. Comfort, cleanliness and convenience, Oxford, UK, Berg. 
Shove, E., Walker, G. \& Brown, S. 2014. Material culture, room temperature and the social organisation of thermal energy. Journal of Material Culture, 19, 113-124.

Spinney, J. 2009. Cycling the City: Movement, Meaning and Method. Geography Compass, 3, 817-835.

Srinivas, T. 2002. Flush with Success: Bathing, Defecation, Worship, and Social Change in South India. Space and Culture, 5, 368-386.

Waitt, G. 2014. Bodies that sweat: the affective responses of young women in Wollongong, New South Wales, Australia. Gender, Place \& Culture, 21, 666-682.

Waitt, G. \& Stanes, E. 2015. Sweating bodies: Men, masculinities, affect, emotion. Geoforum, 59, 3038.

Wallenborn, G. 2013. Extended bodies and the geometry of practices. In: SHOVE, E. \& SPURLING, N. (eds.) Sustainable practices: Social theory and climate change. UK: Routledge.

Wilkinson, C. E., Rees, C. E. \& Knight, L. V. 2007. "From the heart of my bottom": Negotiating humor in focus group discussions. Qualitative Health Research, 17, 411-422. 